\title{
Proper Names: Linguistic Conceptualization of Cultural Continuum
}

\author{
Nataliia Gach \\ Taras Shevchenko National University of Kyiv, Kyiv, Ukraine
}

\begin{abstract}
The article examines the cognitive and pragmatic potential of proper names within literary discourse. Since the question of the semantics of proper names is rather acute within the modern linguistic studies, the research presupposes the analysis of the proper names' functioning on a text level, taking into account their cognitive and cultural meaning. The research is carried out within the analysis of the American literary works of XVIIth-XXth centuries. The method of cognitive discourse analysis helps to interpret the knowledge behind the meaning of proper names. The diachronic scope of the study is the basis for the comparative analysis of the representation of the conceptual sphere elements of the American society in literary works of different epochs. The results of the research show that proper names may represent the elements of cultural-historical continuum of a linguistic community on a text level.
\end{abstract}

Keywords: cognitive discourse analysis, conceptual sphere, literary discourse, proper names

\section{Introduction}

Modern linguistics focuses greatly on the problem of the semantics of proper names, since the question of their meaningfulness undergoes serious debates and unfolds both in linguistic and philosophical dimensions. R. Carnap (1947), J. Searle (1958), K. Donnellan (1966, 1970), S. Kripke (1980), P. van Inwagen (1983, 1997), D. Braun (1993, 2005), F. Adams (1997), M. Reimer (2007), and others made a major contribution to the issue. The aim of the conducted research implies the analysis of the usage of references to the objective reality in literary discourse, the determination of the functions performed by proper names in literary works, and the study of their semantic, pragmatic, and cognitive potential by means of the linguistic-cultural interpretation of texts. The investigation carried out in the framework of critical discourse analysis is based on the American literary works of different genres, in which proper names that contain references to America are used. The diachronic approach to the study helps to distinguish the main elements of the image of the USA, developed by the American community.

\section{Proper Names as Referents to the Conceptual Sphere of a Linguistic Community}

\section{Cognitive Approach to the Analysis of Proper Names}

Being the embodiment and the reflection of culture actualized on the semantic level of linguistic units, a

Nataliia Gach, assistant professor, Ph.D., Department of the Theory and Practice of Translation From English, Taras Shevchenko National University of Kyiv. 
language represents and conceptualizes reality. In such a way, a language influences the development of a collective cultural identity. Linguistic and cultural research of texts presupposes the analysis of both certain linguistic phenomena and language systems in general, taking into account that culturally relevant information may be represented by nominative linguistic units. On a text level such cultural information is realized by means of linguistic units endowed with cultural connotations.

The conducted research implies that proper names can become the bearers of culturally meaningful information, in which case the cognitive approach to their analysis may be applicable. Therefore, proper names are regarded as to be located at two different thresholds: first, between the world of our thoughts, beliefs, and desires and the world of our actions, institutions, and practice; and second, between the linguistic and non-linguistic, between the world of meanings and truth-values and the world of representations and imaginings. Thus, proper names turn out to be important for several reasons. On the one hand, a proper understanding of the ordinary use of proper names illuminates several cognitive phenomena such as language acquisition and use, as well as the nature of thought and belief (intentionality). On the other hand, there is no understanding of proper names without a proper understanding of reference. Thus, proper names also teach us about how our thoughts and assertions relate to the world, thereby teaching us the latter by telling us what the former are about. We have thoughts about how the world is, but we also like to think about how it should be. So, presumably, a proper understanding of reference and intentionality should help to understand not only our claims to knowledge but also our value judgments (Garcia-Ramirez, 2010, p. 1). This conclusion seems to be rather rational, especially in the process of the analysis of a literary work, which is regarded as an organized whole, whose every element is subjected to a certain goal. Therefore, the use of proper names in the context of a whole text is determined by their cognitive and cultural component, and author's intentions.

The majority of linguists claim that proper names are non-descriptional. For example, S. Kripke (1980) argues that proper names are not semantically equivalent to definite descriptions, as they cannot have the same intensions as co-referring definite descriptions, since substituting the one for the other in modal contexts can change truth value. In other words, definite descriptions and proper names make different semantic contributions to modal contexts. The same idea is expressed by K. Donnellan (1970, p. 337), who states that proper names are referring expressions, yet on the surface fail to exhibit any descriptive content. Given definite descriptions as the paradigm, one is forced to look under the surface (which amounts to looking into the user(s) of the name) for the "backing of descriptions" that must be there. He claims that users of a name must be in position to supply a set of identifying descriptions. Small children and even adults often use names without literally being able to describe the referent in sufficient detail to guarantee unique identification (Donnellan, 1970, p. 342).

This principle is also applicable to the analysis of literary works, since by the use of a proper name an author marks out certain characteristics of a referent, the choice of which depends on pragmatic intentions, cultural background, and communicative situation in general. John Searle totally agrees with this opinion by saying that proper names are logically connected with characteristics of the object to which they refer (Searle, 1958, p. 173), because in such a way a referent may provoke different associations depending on the speaker's background knowledge, personal attitude, or pragmatic intentions within a certain communicative situation. Telling names are a convincing example of this remark. However, in this case proper names are close to being semantically equivalent to definite descriptions. 
Certain debates on the issue may also be prompted by the statement of J. Searle (1958, p. 167) that the rules governing the use of a proper name are such that it is used to refer to and not to describe a particular object, that it has reference but not senses. This idea to some extent contravenes the cognitive approach to the research that implies the understanding of nominal linguistic units as units with a certain meaning, which in its turn is revealed in the context of a whole text. Therefore, the conducted research presupposes that certain proper names within a literary discourse can denote and describe, since their usage in a text is determined by certain pragmatic intentions.

\section{Cognitive Theory of Empty Names}

Linguists distinguish empty, non-referring names within the notion of proper names. The main debates concern the question of the semantic content of empty names, which denote make-believe objects that do not exist in the objective reality. Some scientists argue that fictional names (there is confusion between empty and fictional names, the latter of which can also be referred to as empty (Braun, 1993)) lack denotation and contribute no entity to the meaning of a sentence, although S. Kripke (1980), P. van Inwagen (1983, 1997), and others insist that fictional characters are actually existing entities, which refer to real objects or notion in general and convey certain meaning.

According to K. Glüer (2008, p. 2), in ordinary modal contexts names and other simple singular terms occur referentially, which may be called an account of relational modality. It is also hardly to disagree with S. Kripke (1980) that ordinary modal reasoning is de re; when we consider alternative possibilities in ordinary modal reasoning, we are interested in alternative scenarios involving the objects we refer to. We are interested in these very objects, regardless of how the names of them are evaluated with respect to those scenarios. This statement is also applicable to literary characters. From this perspective, every empty name within literary discourse may be regarded as a designator that conveys culturally specific information, and which usage is based on certain pragmatic intentions.

As D. Braun (2005, p. 597) points out, empty names (for example, "Vulcan" and "Sh. Holmes") are meaningful, because they have semantic content. If a name lacks semantic content, then the sentences in which the name appears also lack semantic content. Ordinary speakers so judge, because they bear cognitive relations to these names that are importantly similar to the cognitive relations they bear referring names (Braun, 2005, p. 602). In other words, fictional characters are actually existing abstract artifacts of roughly the same ontological category as novels and plots. Authors create characters when they create their fiction. Their existence supervenes on the pattern of activities of authors and readers, just as the existence of novels does (Braun, 2005, p. 616).

The cognitive theory of empty names contributes greatly to the debates on their meaning. The theory is based on two central theses: cognitivism (referential uses of empty names are intelligible not merely in virtue of semantics and/or pragmatics, but mainly in virtue of the cognitive-general resources they recruit), and representationism (two object-directed attitudes, the content of which is cognitively determined, may be directed toward the same object even if the associated representations have been (cognitively) assigned different referents) (Garcia-Ramirez, 2010, pp. 6-7). Therefore, the cognitive theory of empty names assumes a referentialist semantics for names, according to which the semantic contribution of a proper name is its referent. In doing so, we can extend the same semantic treatment to all referential uses of proper names, including empty names. A 
consequence of this homogenous treatment is that assertions, belief reports, and fictional games that make use of empty names are not intelligible in virtue of their semantics alone. On this view, when using empty names speakers assert, believe, report, and desire the contents of their imaginings (Garcia-Ramirez, 2010, p. 127). Thus, the cognitive theory of empty names implies that in virtue of semantics, all referential uses of names contribute their referent to the content of utterances in which they appear. Within the conducted research empty names are regarded from the point of view of their semantic, pragmatic, and cultural content. The following analysis of the proper names' functioning within literary discourse exemplifies the theoretical aspects mentioned above.

\section{Cognitive-Pragmatic Interpretation of Proper Names Representing America}

\section{Miss Columbia}

Columbia, a poetic name for the United States of America that first appeared in the end of the XVIIth century, originated from the name of Christopher Columbus, and became a symbol of a free country. It was Chief Justice Samuel Sewall, who firstly introduced the name in his work "New Heaven":

It is every where called America: but according to Truth, and Desert; men should rather call it Columbina, from the magnanimous Heroe Christopher Columbus a Genuese, who was manifestly Appointed by GOD to be the Finder out of these Lands... (Sewall, 1697, p. 55)

The lines mentioned above demonstrate the belief that the country's destiny is defined by the agency of Providence that led Christopher Columbus to the new world ("manifestly Appointed by GOD"). On a text level, the capitalized word GOD is used to emphasize this idea. Therefore, religion is proved to be one of the basic values of the American society, implicitly represented by the name of the country.

Phillis Wheatley (1775) was among the first to praise Columbia in his poetic works. The poem "To His Excellency George Washington" represents basic concepts connected with the name:

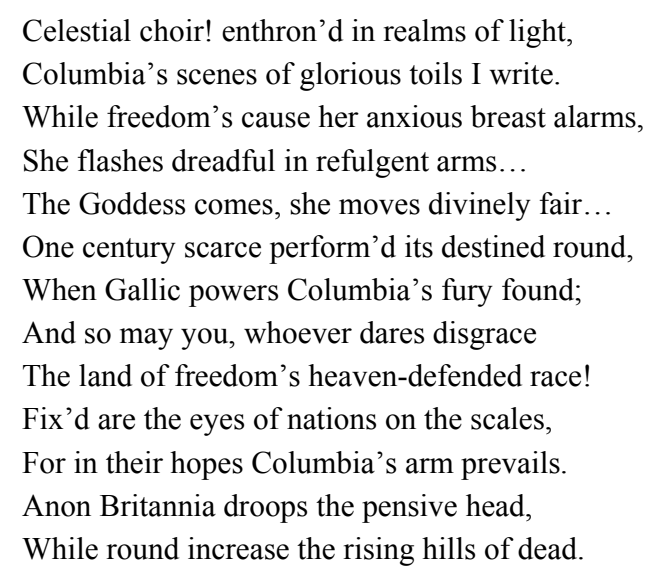

The poem is based on the opposition of the new state ("Columbia") to the Old World embodied by Great Britain ("Gallic powers", "Britannia"). The notion of independence is represented as the essential one for the America, which is worth fighting for ("freedom's cause"). This idea is emphasized by such word-combinations as "Columbia's fury" and "flashes dreadful", in which the lexemes "fury" and "dreadful" intensify the intentions to struggle for the native country. In order to stress on the conviction in America's victory in battles for independence ("Columbia's arm prevails. / Anon Britannia droops the pensive head..."), the author uses such 
tropes as metaphor (personification) and metonymy which endow the poem with poetic meaning and spiritualize the high cause of fight. However, the concept of independence is inalienable from the religious values of the Americans ("land of freedom's heaven-defended race"). P. Wheatley describes the United States of America as a country whose mission is defined by God and therefore, cannot fail.

Interestingly, that the concept of freedom and independence is also represented visually, as Columbia's traditional garment (Greek robes often adorned with the stars and stripes, and liberty cap) embodies the main value of the American society of those times. The Phrygian or liberty cap symbolizes freedom and the pursuit of liberty, which was of pivotal importance in the times of the American Revolutionary War between the Kingdom of Great Britain and the North American colonies. It is remarkable that in the Republican Rome such a cap served as a symbol of freemen endowed not only with personal freedom, but also with freedom of citizens, which guaranteed the right to vote. In such a way, the independence is presented as a prevailing value of the American society.

The similar idea is expressed in the poem by O. W. Holmes" "Hail, Columbia!" (1798):

$$
\begin{aligned}
& \text {...Firm-united-let us be, } \\
& \text { Rallying round our Liberty; } \\
& \text { As a band of brothers join'd, } \\
& \text { Peace and safety we shall find... }
\end{aligned}
$$

The idea of unity on the way to freedom is strengthened by the feeling of kinship between the members of the American society ("as a band of brothers join'd"). The syntactic construction "let us" also contributes to the unfolding of the main meaning of the poem, as its cognitive and pragmatic features point at the unity of free and equal individuals who share the same goals.

The perception of freedom as a sacred value of the American nation is represented in the poem of E. Wilcox "Our Atlas" (1917):

O Liberty, who lights the world with rays that come from God,

Shine on Columbia's troubled track, and make it bright and broad;

Shine on each heart, and give it strength to meet its pains and losses,

And give supernal strength to one who bears the whole world's crosses...

Characteristic for the Americans is the understanding of liberty as a Godly blessing ("lights the world with rays that come from God"), which determines the development of the whole society ("Shine on Columbia's troubled track") and of every individual ("Shine on each heart"). On a text level the stylistic device of syntactic parallelism ("Shine on... / Shine on...") is used to emphasize such an idea. The author also uses the personification of the notion "liberty" and endows it with sacred features ("supernal strength") that appear to be principal in the process of the country's development.

The poem "Independence Ode" by E. Wilcox (1917) also brings the concept of America's independence to the forefront:

Columbia, fair queen in your glory!

Columbia, the pride of the earth!

We crown you with song-wreath and story;

We honour the day of your birth!...

You braved, to be free, on that day... 
Since the chains and the shackles are broken,

And citizens now replace slaves,

Since the hearts of your heroes have spoken

How dear they held freedom- by graves.

The implicit opposition of the country's historical past, and the period of its independence and prosperity points at the importance of the concept of freedom for the American society. The author's intentions are realized by means of the comparison of America with a beautiful queen ("fair queen"), "the pride of the earth". Moreover, E. Wilcox opposes such concepts as freedom and slavery ("chains and the shackles are broken"; "citizens now replace slaves"). The lexeme "citizens" is defining, as it implies the status of equality for all members of the American society. Therefore, it becomes clear that the concept of freedom reveals not only the idea of the country's independence, but also the liberties of every individual.

Thus, the proper name Columbia represents the following concepts: freedom, equality, and religion. However, it loses its allegorical character and cognitive potential to a great extent in the first part of the XXth century, which can be explained by the historical processes in the society. During the times of the American Revolutionary War and the Civil War, the concepts mentioned above represented the basis for the country's development, and defined its direction. The change in political, economic, and social interests led to the change of values and ideals. Therefore, the study shows that the proper name Columbia is the embodiment of the United States of America, which represents the basic concepts and values of the American society of the XVIIth-XXth centuries.

\section{Brother Jonathan}

Brother Jonathan, the national personification of the United States of America, appeared during the American War for Independence. One of the best known stories depicting Brother Jonathan is "The diverting history of John Bull and Brother Jonathan" by James Kirke Paulding, published in 1827. The main plot unfolds around the opposition of John Bull (personification of Great Britain) and Brother Jonathan (personification of the New World). The concept of independence is central to the story. Consider the following lines (Paulding, 1827, pp. 7-8):

While Jonathan was outgrowing his strength in this way, Bull kept on picking his pockets of every penny he could scrape together; till at last, one day when the Squire was even more than usually pressing in his demands, which he accompanied with threats, Jonathan started up in s furious passion, and threw the Tea Kettle at the old man's head. The choleric Bull was hereupon exceedingly enraged, rebellious rascal, seized him by the collar, and forthwith a furious scuffle ensued. This lasted a long time; for the Squire, though in years, was a capital boxer, and of most excellent bottom. At last, however, Jonathan got him under, and before he would let him up, made his sign a paper giving up all claim to the farms, an acknowledging the fee-simple to be in Jonathan forever.

The passage familiarizes readers with rather strenuous relationships between Great Britain and America, the latter of which is depicted as the son of the former. Being dependent on Great Britain, America was deprived of political and therefore, economic independence ("Bull kept on picking his pockets of every penny he could scrape together"). Of course, such state of affairs could not satisfy the newly formed country, which led to the rebellion known as the Boston Tea Party ("Jonathan started up in s furious passion, and threw the Tea Kettle at the old man's head"). This event resulted in the escalated crisis and finally led to the American Revolutionary War against the Kingdom of Great Britain, which marked the rise of the new independent country ("Jonathan...made his sign a paper giving up all claim to the farms..."). 
The author uses multiple stylistic devices for the opposition of two characters. Bull's greed for money is represented by the word-combination "scrape together", which points at the insatiability of Great Britain's interests and needs. Moreover, J. Paulding criticizes the political methods of the country, based on threats, intimidation ("usually pressing in his demands, which he accompanied with threats"), and brute force ("the choleric Bull...seized him by the collar, and forthwith a furious scuffle ensued"). The adjective "choleric", which is used to describe Squire Bull, has a negative meaning and reveals author's attitude to the character and to the country it embodies.

The context of the whole work proves that the thriving for independence is rooted not only in political or economic, but also in religious disagreements:

One day he got into a dispute with his youngest son, Jonathan, who was familiarly called Brother Jonathan, about whether churches ought to be called churches or meeting-houses; and whether steeples were not an abomination... After this, he made the houses so disagreeable to him, that Jonathan, though as hard as a pine knot, and as tough as leather, could bear it no longer. Taking his gun and his axe, he put himself in a boat, and paddled over the mill-pond to some new lands belonging to the Squire, intending to settle them, and build a meeting-house without a steeple, as soon he grew rich enough. (Paulding, 1827, pp. 4-5)

The author depicts Jonathan as a puritan, who advocates the changes within the Church of England. The parallel with the real events of those times is obvious. As the group of English Protestants, the puritans wanted to eliminate some Christian practices, which were widely used. Such changes concerned not only spiritual, but also rather materialistic matters, for example, the abolition to transform the churches from within ("a dispute...whether steeples were not an abomination”). In the sphere of church policy, the disputes arose around the necessity to separate from other Christians by establishing autonomous gathered churches ("a dispute... whether churches ought to be called churches or meeting-houses"). Therefore, it can be concluded that religious freedom was one of the cornerstones of the American independence.

Except of the concepts of independence and religion, the name Brother Jonathan is used for the representation of the concept of power: "But for all this, in a little time, Jonathan grew up to be very large of his age; and became a tall, stout, double-jointed, broad-footed cub of a fellow" (Paulding, 1827, p. 6).

Having used the stylistic device of personification, the author presents the United States of America as a strong young man, emphasizing in such a way the power and strength of the newly born country.

The idea of the nation's power is tightly bound to the notion of its prosperity and wealth, which is demonstrated by the following lines:

Having but one exclusive road to prosperity, they conclude there is no other way but this in the world, that what is their interest must be every body's interest, and that whenever that is effected, the whole world must be turned upside down. (Paulding, 1827, p. 80)

The given example presents the idea of leadership of the American nation, based on its might and wealth, which in their turn enable America to rule the world. However, the concepts analyzed are closely intertwined with the concept of family, which is perceived as a cornerstone of a powerful and invincible state:

These family disturbances used to annoy Jonathan not a little; but, however, he found great reason to be satisfied with his wife, who turned out to be a very notable woman, and right thrifty housekeeper...by her advice and assistance, Jonathan prospered in all his affairs; his farms grew more valuable every year; the number of his tenants increased rapidly, 
and so successful was he in all his speculations, that the old neighbors prophesied if Jonathan lived to be an old man, he would be one of the richest of his day. (Paulding, 1827, p. 11)

The concept of prosperity is explicitly represented by such lexemes as "prospered", "valuable", "successful", and "the richest". However, obviously, the roots to the country's wealth lay in family values, since a strong and close-knit family is a key to success. The author stresses upon two traits of a woman that are important for the American man to be successful. These are notable blood ("a very notable woman") and thriftiness of a housekeeper ("right thrifty housekeeper"). Within the context of the whole text, it becomes clear that Mrs. Jonathan is the personification of France, the country which played a significant role in the development of the USA. In 1778, after the beginning of the American Revolutionary War, France signed an alliance with the North American colonies in order to revenge for the events of 1763. Moreover, in 1803 France sold Louisiana to the United States of America, which incredibly increased the territory of the latter ("the number of his tenants increased rapidly").

The analyzed examples prove that the proper name Brother Jonathan is the personification of the United States of America, and cannot be called empty, since it has a designator. The mentioned name actualizes the following concepts of the conceptual sphere of the American society: independence, religion, power, prosperity, and family. However, with time the name Brother Jonathan dropped out of usage, as Uncle Sam came into existence.

\section{Uncle Sam}

Uncle Sam as the personification of America (the name is a reversed acronym of the US), or to be more specific of the American government, appeared during the Anglo-American War of 1812. In literature, it was firstly introduced in a book by Frederick Augustus Fidfaddy, Esq. The Adventures of Uncle Sam in Search After His Lost Honor in 1816. The following analysis of the book provides the basis for the research of the elements of the conceptual sphere of the American community, since it brings the most important of them to the forefront. It is obvious that religion has always been one of the key values of the American society. That is why the references to the religion are also present in the book: "This Thomas was moreover, of a religious turn of mind for, whereas Uncle Sam acknowledged only one God, Thomas professed to believe in twenty or none as occasion required" (Fidfaddy, 1816, p. 10).

Uncle Sam is described as a pious man with unwavering religious principles, which is stressed upon on the level of opposition of Uncle Sam to others for whom religion is a matter of occasion that may be changed with the purpose to gain some benefit from the situation ("Thomas professed to believe in twenty or none as occasion required").

Except of the concept of religion, the concept of democracy has always been of pivotal importance for the Americans. Consider the following lines:

Well, said mine Uncle, Sangrado, what is the serious world about? What news of Bull, what of Nap, what says the chief Steward, do we have war or peace? I begin to grow tired of this state of things. If we have war, Sangrado, I must tell you I am not a little fearful of this nag Democracy, a fine Beast, $\mathrm{O}$ as true as the needle, a fine Beast to ride to Elections on and manage state affairs in time of peace; but in war, when the battle rages, I am afraid - ah I am afraid the restive truant won't like the smell of powder; ah and its no trifling affair to meet John Bull in the field, I've try'd it once I know all about it. I had a different horse when I met him at Bunker-hill, at Saratoga, at Trenton and Yorktown. - Ah the good old horse Buckskin-Yankee-George could manage him. (Fidfaddy, 1816, p. 23) 
The understanding of democracy as the key value for the American society is represented through the opposition of war and peace, as these two states of affairs demand different approaches to the managing strategies. Interestingly, that democracy is not considered as the best governing strategy in the state of war, which is emphasized by the choice of linguistic units. Within the word-combination "nag Democracy", the lexeme "nag" has rather negative connotation, meaning an old and worthless horse, useless to win a battle. Such an idea is intensified by the phrase "the restive truant won't like the smell of powder". These words explain the core meaning of the concept democracy to the fullest extent, as democracy presupposes the power of people, led by principles of equality, freedom, and justice. However, these principles are not applicable to the wartime, when the decisions that guarantee the victory of certain ideals ("Free trade and Sailor's rights") have to be firm and sometimes unpopular.

In this context the notion of the nation leader arises. Being the personification of the American government, Uncle Sam is represented as a person who understands the nature of thongs, and is able to make right decisions ("I had a different horse when I met him at Bunker-hill, at Saratoga, at Trenton and Yorktown. - Ah the good old horse Buckskin-Yankee-George could manage him"). By means of the enumeration of battle places during the American Revolutionary War, the author hints at the American victory in the War of Independence achieved by resistance to enemy and fight for freedom: "Uncle Sam is no coward; no, Bunker-hill now that" (Fidfaddy, 1816, p. 26). On the stylistic level, this idea is highlighted by the repetition of the negative particle no, which negates the cowardice of the Americans and draws attention of readers to the event that demonstrates their courage (Bunker-hill battle).

Nevertheless, democracy is regarded as the best system of government in the time of peace ("a fine Beast, $\mathrm{O}$ as true as the needle"). An oxymoron "fine Beast" stresses upon the hidden powerful forces of democracy as a ruling style, since it conforms with people's desire to live in a peaceful and free society, and therefore, brings victory to those politicians who can guarantee such a way of life to the nation ("a fine Beast to ride to Elections on and manage state affairs in time of peace").

The conducted analysis proves that the concept of independence (in its broad meaning) is the basic one in the conceptual sphere of the American society: "What does all this mean? Boundaries, Ratifications, Indians, Slaves, obligations? What, we didn't' go to war for this trumpery! Blockade's, Sailor's rights... Have we no redress, what?" (Fidfaddy, 1816, p. 131).

The words of Uncle Sam mentioned above exemplify true intentions of the American government while entering the war with Great Britain. The slogan "Free Trade and Sailor's Rights" reflects the interest of the Americans in free trade and the protection of sailors from impressment. Therefore, economic independence turns out to be as important for the new state as personal freedoms of its people. The analyzed lines, however, oppose the interest in economic independence to other values of the American society, such as power and prosperity (the extension of boundaries), person's rights and equality (the rights of Native Americans and Afro-Americans), etc. The author though, represents Uncle Sam hypocritical to some extent, as the Revolutionary War, except of the economic and political independence of the United States of America, resulted among all in the affiliation of new territories and reserving land for the Indians. Thus, America gained independence and grew into powerful state.

Subsequently, the text analysis shows that the proper name Uncle Sam is used for the representation of such concepts as independence, religion, and democracy. 


\section{Conclusion}

The results of the research demonstrate that proper name under analysis represent the elements of the US conceptual sphere of the XVIIth-XXth centuries. The literary images behind the names impersonate different aspects of the American history, and its economic and cultural development. The images under consideration were created with the aim to portray the strength of the country, justice of its laws, and equality of its citizens. That is why the cultural and cognitive analysis of the proper names representing America enables to trace the emergence of the basic values of the American society, to which belong religion, independence, and freedom, democracy, power, prosperity, and family. It is proved that certain proper names have referents, and cannot be called empty because of their pragmatic and cultural meaning.

\section{References}

Abbott, B. (2011). Support for individual concepts. Linguistic and Philosophical Investigations, 10, 1-23.

Adams, F., Fuller G., \& Stecker R. (1997). The semantics of fictional names. Pacific Philosophical Quarterly, 78(2), $128-148$.

Braun, D. (1993). Empty names. Noûs, 27(4), 449-469.

Braun, D. (2005). Empty names, fictional names, mythical names. Noûs, 39, 596-631.

Carnap, R. (1947). Meaning and necessity: A study in semantics and modal logic. Chicago: University of Chicago Press.

Donnellan, K. S. (1966). Reference and definite descriptions. The Philosophical Review, 75(3), 281-304.

Donnellan, K. S. (1970). Proper names and identifying descriptions. Synthese, 21(3/4), 335-358.

Fidfaddy, F. A. (1816). The adventures of Uncle Sam in search after his lost honor. Retrieved from https://archive.org/details/advunclesam00fidfrich

Garcia-Ramirez, E. (2010). Proper names: A cognitive-philosophical study. Retrieved from http://deepblue.lib.umich.edu/bitstream/handle/2027.42/75808/eduardga_1.pdf?sequence=1

Glüer, K., \& Pagin, P. (2008). Relational modality. Journal of Logic, Language and Information, 17, 307-322.

Holmes, O. W. (1798). Hail, Columbia! Retrieved from http://www.readbookonline.net/readOnLine/7089/

Inwagen van, P. (1983). Fiction and metaphysics. Philosophy and Literature, 7, 67-77.

Inwagen van, P. (1997). Creatures of fiction. American Philosophical Quarterly, 14(4), 299-308.

Kripke, S. (1980). Naming and necessity. Lectures given to the Princeton University Philosophy Colloquium. Retrieved from http://www.class.uh.edu/phil/garson/NamingandNecessity.pdf

Paulding, J. K. (1827). The diverting history of John Bull and Brother Jonathan. Retrieved from https://archive.org/details/divertinghistor00paulgoog

Riemer, M. (2007). Empty names: Communicative value without semantic value. Philosophy and Phenomenological Research, 74(3), 738-747.

Searle, J. R. (1958). Proper names. Mind, 67, 166-173.

Sewall, S. (1697). The new heaven. Boston: Green and Allen. Retrieved from http://olivercowdery.com/texts/1697Sewl.htm

Wheatley, P. (1775). To his excellency general Washington. Retrieved from $\mathrm{http} / /$ www.poets.org/poetsorg/poem/his-excellency-general-washington

Wilcox, E. W. (1917). Independence ode. Retrieved from http://www.ellawheelerwilcox.org/poems/pindepen.htm

Wilcox, E. W. (1917). Our Atlas. Retrieved from http://www.poemhunter.com/poem/our-atlas/ 